\title{
Processo de envelhecimento: percepções de docentes da rede básica de educação do município de Uruguaiana-RS
}

\author{
Aging process: perceptions of elementary school teachers of the municipal education in \\ Uruguaiana-RS, Brazil
}

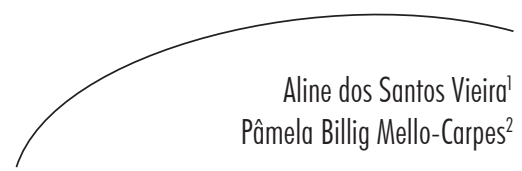

Resumo

Objetivo: Verificar a percepção do processo de envelhecimento humano pelos docentes da rede pública de educação básica de Uruguaiana-RS. Métodos: Trata-se de estudo descritivo, cuja amostra foi composta por 13 educadores que responderam a um questionário, previamente validado por pesquisadores da área, contendo oito perguntas. As respostas foram posteriormente lidas, analisadas e categorizadas por meio da técnica de análise de conteúdo. Resultados: Encontraram-se aspectos positivos e negativos na investigação, de acordo com os valores socioculturais de cada docente. Os educadores encaram o envelhecimento como uma etapa de transferência e partilha de experiências e conhecimentos e, apesar das adversidades e problemas de saúde que supostamente enfrentarão, têm uma visão otimista desse processo. Conclusões: Os relatos afirmaram que a qualidade de vida futura é reflexo da atual. Assim, a autopercepção pode levar à mudança de comportamento de uma comunidade, proporcionando uma ótica diferente desse ciclo biológico. Ressalta-se a importância de se investir em estudos de conscientização para eliminar preconceitos e estereótipos comuns às pessoas em relação a essa etapa da vida, especialmente junto a esse público que é formador de opinião.

\section{Abstract}

Objective: To assess the perception about the human aging process of teachers from public elementary schools in the city of Uruguaiana, state of Rio Grande do Sul, Brazil. Methods: This is a descriptive study, with sample composed by 13 teachers who responded to a questionnaire previously validated by researchers, containing eight questions, which was subsequently read, analyzed and categorized through the content analysis technique. Results: There were positives and negatives in that investigation, in accordance with the sociocultural values of each teacher. Educators see aging as a step for the transfer and sharing of experiences and knowledge, and in spite of adversity and

\section{Palavras-chave:}

Envelhecimento. Idoso.

Docentes. Percepção.

Key words: Aging. Elderly. Faculty. Perception.

\footnotetext{
Curso de Farmácia, Programa de Bolsa Iniciação Científica, Grupo de Pesquisa em Fisiologia. Universidade Federal do Pampa. Uruguaiana, RS, Brasil.

2 Núcleo de Estudos e Pesquisa do Envelhecimento, Grupo de Pesquisa em Fisiologia. Programa de Pósgraduação em Bioquímica. Universidade Federal do Pampa. Uruguaiana, RS, Brasil.
} 
health problems that supposedly will face, they have an optimistic view of this process. Conclusions: The reports stated that the future quality of life is a reflection of the current, so self-perception can change the behavior of a community by providing different perspectives of this biological cycle. We emphasize the importance of investing in studies to suppress prejudices and stereotypes common to people concerning this stage of life, especially with this audience that is an opinion maker.

\section{INTRODUÇÃOO}

O envelhecimento deve ser concebido como um processo multidimensional, ${ }^{1}$ uma vez que, em sua totalidade, pode ser compreendido como um fenômeno biológico com consequências psicológicas. Assim, a velhice tem uma dimensão existencial, que modifica a relação da pessoa com o tempo, gerando mudanças em suas relações com o mundo e com sua própria história. ${ }^{2} \mathrm{Em}$ 1990, Santos ${ }^{3}$ já questionava a compreensão do envelhecimento humano dentro das sociedades; desde então, estudos que argumentam sobre as concepções a respeito da velhice são cada vez mais frequentes. ${ }^{4-9}$

Considerando que as características pessoais, bem como os aspectos psicossocioculturais, interferem na maneira de olhar o envelhecimento, a possibilidade de envelhecer de maneira bemsucedida vai depender, dentre outros fatores, da história de vida e da forma como cada um entende o processo de envelhecimento e a velhice. ${ }^{10}$

As diferentes reflexões que alguns grupos sociais têm sobre o envelhecimento, aliadas à concepção veiculada pelos meios de comunicação, muitas vezes arraigada de estereótipos, pode ou não levar à exclusão ou valorização dos idosos na comunidade. A imagem feita por cada indivíduo e salientada pela opinião de um ou outro crítico modela a visão das comunidades em relação aos idosos e ao envelhecimento, o que tende a desencadear insegurança para os idosos, fomentar o preconceito entre as gerações e gerar medo de envelhecer, devido à incerteza de como será (ou como está sendo) o próprio envelhecimento.?
A fim de evitar que esta visão esteja ligada ao processo de envelhecimento e, principalmente, à figura da pessoa idosa, há a necessidade de conscientizar a população em seus mais diversos segmentos. Dentre as parcelas da população que desempenham papel fundamental em oportunizar e intermediar tais ações de conscientização, está a dos professores, uma vez que estes estão envolvidos na construção de novos conhecimentos e também são os responsáveis em transformar a aula em um ambiente adequado para que o aluno faça parte da construção do saber. ${ }^{11}$

Freire $^{12}$ relata que, na tarefa docente, o professor não deve ser apenas um transmissor de conhecimentos, mas possibilitar maneiras e métodos para sua produção, considerando o educador e o educando como seres sóciohistórico-culturais - ou seja, na prática de ensinaraprender, encontram-se presentes experiências no aspecto político, cultural, ideológico, ético e pedagógico.

Diante desses fatores, é imprescindível o emprego de ações e estudos que discutam a problemática do envelhecimento em todos os segmentos e relacionado aos mais variados aspectos sociais. Considerando que os docentes estão em contato direto com estudantes e o ambiente escolar é um potencial local para se discutir a importância social do idoso, seus direitos, deveres, peculiaridades, e iniciar a preparação para a terceira idade, buscou-se por meio deste estudo conhecer as percepções dos educadores da rede pública de ensino de Uruguaiana-RS acerca do processo de envelhecimento humano. 


\section{METODOLOGIA}

A amostra deste estudo descritivo foi composta por 13 docentes da rede pública de educação básica de Uruguaiana-RS, que participaram voluntariamente. Esta ação fez parte do Curso de Capacitação para Trabalhar o Envelhecimento na Escola, realizado pelo Núcleo de Estudos e Pesquisa do Envelhecimento (NEPE) da Universidade Federal do Pampa (UNIPAMPA), campus Uruguaiana, Rio Grande do Sul. Dos 25 docentes integrantes da rede pública de educação básica, 13 aceitaram participar do curso, bem como deste estudo.
Com o objetivo de verificar a percepção dos docentes acerca do envelhecimento, utilizou-se um questionário construído pelos pesquisadores. Após sua construção, o questionário foi enviado a dois pesquisadores da área, um da Região Sudeste e um da Região Sul do Brasil, não envolvidos com o estudo, com uma descrição que incluía o objetivo de cada uma das questões. Os pesquisadores validaram o questionário verificando se as questões estavam de acordo com o objetivo de forma clara e, em alguns casos, sugerindo modificações. As oito perguntas que compuseram o questionário, bem como seus objetivos, estão elucidados no quadro 1.

Quadro 1 - Questões utilizadas e objetivos de cada uma. Uruguaiana-RS, 2011.

\begin{tabular}{|l|l|}
\hline \multicolumn{1}{|c|}{ Questão } & \multicolumn{1}{|c|}{ Objetivo } \\
\hline $\begin{array}{l}\text { 1. O que pensa ou o que lhe vem à cabeça quando } \\
\text { escuta a palavra envelhecimento/ envelhecer/ } \\
\text { idoso? }\end{array}$ & $\begin{array}{l}\text { Verificar o que os docentes pensam sobre o processo } \\
\text { de envelhecimento de um modo geral. }\end{array}$ \\
\hline 2. Para você, o que é envelhecimento? & $\begin{array}{l}\text { Verificar como os docentes caracterizam o processo } \\
\text { de envelhecimento. }\end{array}$ \\
\hline 3. Como você caracteriza uma pessoa idosa? & $\begin{array}{l}\text { Verificar o que os docentes pensam sobre o idoso de } \\
\text { um modo geral. }\end{array}$ \\
\hline 4. Você pensa sobre o seu envelhecimento? Como \\
vai ser quando isso acontecer? & $\begin{array}{l}\text { Verificar se os docentes pensam em como será o seu } \\
\text { processo de envelhecimento e se preparam de alguma } \\
\text { forma para esta etapa da vida. }\end{array}$ \\
\hline 5. Como você pensa que será sua velhice? & $\begin{array}{l}\text { Verificar quais as expectativas dos docentes sobre a } \\
\text { velhice. }\end{array}$ \\
\hline 6. Em sua opinião, quais os pontos positivos e e & $\begin{array}{l}\text { Verificar quais são os aspectos positivos e negativos } \\
\text { no processo de envelhecimento aos olhos dos } \\
\text { nocentes entrevistados. }\end{array}$ \\
\hline 7. Como é envelhecer bem? & $\begin{array}{l}\text { Verificar como os docentes caracterizam o } \\
\text { envelhecimento saudável. }\end{array}$ \\
\hline 8. Pensa que terá alguma dificuldade na velhice? & $\begin{array}{l}\text { Verificar quais as possíveis dificuldades que os } \\
\text { docentes veem no envelhecimento. }\end{array}$ \\
\hline
\end{tabular}

Após explicar os objetivos da pesquisa e realizar a apresentação do questionário, conforme o quadro 1, solicitou-se aos docentes que escrevessem individualmente suas respostas, utilizando caneta e papel. Posteriormente, as respostas foram lidas, interpretadas, categorizadas e descritas, com base no agrupamento de temáticas que emergiram das respostas dos docentes. A coleta de dados foi realizada no campus da Universidade Federal do Pampa, na cidade de Uruguaiana-RS, no período de agosto a outubro de 2011. A figura 1 apresenta um esquema metodológico do estudo. 


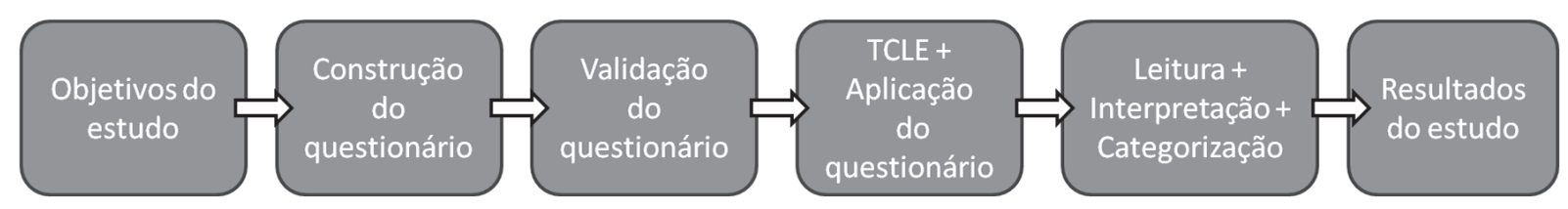

Figura 1 - Esquema metodológico do estudo.

Esta pesquisa de cunho qualitativo não teve o intuito de quantificar dados, mas realizar um processo de análise de conteúdo das respostas. Assim, pode ser considerada descritiva, pois descreve as características de certa população ou fenômeno.

Em Minayo, ${ }^{13}$ encontra-se que a análise de conteúdo parte de uma literatura de primeiro plano para atingir um nível mais aprofundado: aquele que ultrapassa os significados manifestos. Para tanto, a análise de conteúdo relaciona estruturas semânticas com estruturas sociológicas dos enunciados, ou seja, articula a superfície dos textos descrita.

Com base na literatura supracitada, foram descritos os principais resultados deste estudo, procurando estabelecer uma conexão multidimensional entre as percepções dos educadores e o processo de envelhecimento como um todo.

O estudo é parte de um projeto de pesquisa mais amplo, aprovado pelo Comitê de Ética em Pesquisa da UNIPAMPA (carta de aprovação 024/2010) em 10 de novembro de 2010, e cumpriu os princípios éticos contidos na Declaração de Helsinque, além de atender à legislação vigente em todas as etapas do trabalho. Todos os participantes assinaram o Termo de Consentimento Livre e Esclarecido (TCLE), concordando em participar da pesquisa.

\section{RESULTADOS E DISCUSSÃO}

O grupo de docentes participantes da pesquisa foi constituído por 12 mulheres e um homem. A idade média da amostra foi $36,54( \pm 7,76)$ anos. Os docentes tinham formação superior em licenciatura em Biologia, Educação Física, Matemática e Química, sem atuação direta junto à população idosa, porém com atuação junto a crianças e adolescentes em idade escolar.

Com base na análise das respostas, constatouse que a maioria $(84,61 \%)$ dos docentes percebe o processo de envelhecimento como uma etapa de transmissão de experiências e sabedoria, que proporciona prazer em vivenciá-la, mas que frequentemente apresenta dificuldades, conforme observado nas falas:

[O envelhecimento é] uma conquista, por ter ido tão longe, mas com uma mente aberta e dinâmica.

É uma experiência de vida que tem que ser passada para os mais jovens.

[Os idosos são] pessoas que, mesmo com dificuldades, têm condições de contribuir, devido à vasta gama de experiências.

Palavras como "dificuldade", "solidão", "preocupação", "limitação", "exclusão da sociedade" e "medo" foram frequentemente utilizadas para descrever o envelhecimento, o que retrata a visão estereotipada que alguns têm desse processo, uma vez que o relacionam a fragilidade, doenças e perda de vitalidade. ${ }^{8}$

Apesar da presença desses sentimentos citados quando perguntados sobre "o que é o envelhecimento", grande parte das respostas (77\%) foi positiva. Os entrevistados assumiram uma postura de aceitação, encarando o envelhecimento como um processo natural, que deve ser vivido da melhor forma possível. Algumas das respostas dos docentes relacionadas a este aspecto foram: 
Realizar atividades com menos condições do que quando era jovem, mas com muito mais sabedoria.

Inevitável, porém devemos saber o que fazer para torná-lo natural e parte da vida de todos.

Penso que o envelhecimento é uma fase ou etapa que já vivemos e adquirimos sabedoria, experiências...

Fazparte da vida de todos, é natural e devemos encarálo da melhor maneira possivel.

É mais uma das etapas da vida, um novo tempo.

Assim, verificou-se que grande parte $(77 \%)$ dos docentes não percebe velhice como uma doença que debilita o corpo. Ao contrário, houve clara constatação de que o corpo e a mente realizam com desenvoltura as diversas funções rotineiras, desafiando a idade cronológica. ${ }^{10}$

Três docentes (23\%) evidenciaram em suas falas o processo de envelhecimento como algo negativo:

Penso que é uma nova fase de vida e que muitas vezes não conseguiremos mais realizar o que fazíamos em anos anteriores.

Muita dificuldade, principalmente na saúde. E também medo de ficar sozinha.

Pessoa [o idoso] com dificuldades físicas, excluidas da sociedade.

Foram recorrentes palavras como "idade", "cabelos brancos"," marcas biológicas" e concepções do idoso como "uma pessoa com vontade de viver, porém na caminhada encontra muitas dificuldades até a aceitação", confirmando a predominância da concepção biológica do envelhecimento. De acordo com Cabral, ${ }^{14}$ isto torna o entendimento da velhice fragmentado, já que o processo de envelhecimento envolve múltiplas dimensões que dão um caráter complexo ao fenômeno, não podendo ser compreendido por uma única ótica.

Os docentes revelaram não pensar no seu envelhecimento no presente, porém acreditam que terão uma velhice ativa, alegre, saudável e tranquila. Ao mesmo tempo, alguns mostraram certa preocupação com a aparência, apresentando uma inclinação para negar o envelhecimento:

Espero que muito ativa e disponivel [a velhice] para auxiliar onde for possivel.

Nem tenho ideia [de como será o envelhecimento], mas espero que da maneira mais saudável possivel.

Me imagino um velho ativo que não pode ficar sem fazer nada, parado, quieto.

Não me imagino idosa, parece que não serei, mas chegaremos lá.

Respeitada por minhas filhas, muito ativa e bem maquiada, evitando a idade. Carinhosa com todos, indo até as minhas limitações.

A negativa de que o envelhecimento se faz presente pode ser justificada pela cultura social, que privilegia a juventude e a beleza. Com isso, as pessoas idosas tendem a evitar a classificação da velhice. Para isso recorrem aos mecanismos tradicionais, de pintar o cabelo e maquiar-se, submeter-se a procedimentos cirúrgicos no corpo, seguindo o que a sociedade dita como moda, temas de interesse e condutas para se manterem jovens, inclusive negando a idade,${ }^{15}$ conforme evidenciado em algumas falas.

Dos 13 docentes entrevistados, 77\% citaram a "experiência" como um ponto positivo do processo de envelhecimento, ao passo que a "sabedoria" foi o segundo ponto mais citado (50\%). Afirmaram também que com o envelhecimento possuirão mais tempo para si, para a realização de atividades físicas.

Com relação aos pontos negativos, foram recorrentes relatos de doenças e as limitações e impotência que estas causam (61,5\%), além do medo do abandono por parte da família e amigos nessa fase da vida, restando-lhes uma vivência de solidão e abandono.

É importante observar que ao mesmo tempo em que mencionaram os problemas de saúde e classificaram a velhice como uma fase de 
novos cuidados, os docentes relataram que na velhice poderão desfrutar de melhor qualidade de vida, em função de dispor de tempo para a família e para a prática de exercícios, sendo que, contraditoriamente, a disponibilidade de tempo é atribuída à impossibilidade de realizar outras atividades para evitar problemas de saúde.

A prática de atividade física regular e a adoção de um estilo de vida ativo são necessários para a promoção da saúde e qualidade de vida durante o processo de envelhecimento, ${ }^{16}$ uma vez que são associados à prevenção de doenças, manutenção de um corpo forte e resistente, além da melhoria nas relações sociais, devido à convivência em grupo, propiciadas pelo contato com outras pessoas durante o envolvimento com a prática, ${ }^{17}$ além de prevenir e evitar o surgimento de doenças crônicas. ${ }^{18}$ Dessa forma, a atividade física e uma vida ativa devem ser estimuladas não somente no idoso, mas precocemente, como forma de prevenir e controlar as doenças crônicas e manter a independência funcional, ${ }^{16}$ além de ser uma possível forma de preparação para o envelhecimento. ${ }^{17}$

Todos os docentes associaram um bom processo de envelhecimento a boa alimentação e qualidade de vida, ausência de doenças e problemas, além de poder realizar atividades:

É estar de bem com a vida, é atribuir algum horário do dia para atividade física. É aceitar as pessoas.

[Manter a] mente ativa mesmo que não tenha condições fisicas. Se possivel com atividades físicas e muitas atividades mentais.

É ter vida ativa, ser como éramos jovens quanto aos pensamentos e poder trabalhar as limitaçoes com entusiasmo.

Viver bem, considerando todos os aspectos - biológicos, físicos, sociais, psicológicos.

Ainda revelaram que deve haver relação entre a saúde do corpo e da alma, demonstrando uma visão otimista e positiva frente aos possíveis obstáculos que poderão enfrentar:
Men estado de saúde agora é muito bom, espero na velhice ter uma vida saudável, tranquila, participar de grupo de terceira idade com atividade física, viagens.

O que faço boje refletirá bem ou não ao meu organismo na velhice.

Terei alguma dificuldade talvę física, mas com muita atividade mental. Buscando também a física.

Não me sinto velho com 59 anos. A velhice está na mente e não no corpo.

Pode-se observar que o fato de a longevidade ocupar um espaço significativo está levando a população a se adaptar à nova realidade, valorizando a capacidade e os potenciais deste grupo, e desenvolvendo estruturas que atendam a suas necessidades. ${ }^{?}$

No entendimento de Veras, ${ }^{19}$ adicionar qualidade aos anos vividos implica manutenção da autonomia, autossatisfação, participação e a possibilidade de atuar em variados contextos sociais. Assim como a descoberta de valores e crenças, a valorização do conhecimento e o desejo de viver uma velhice com mais qualidade de vida e oportunidades são fundamentais para superar todas as dificuldades que serão encontradas ao longo desse gradual e ininterrupto processo. ${ }^{20}$

Uma das limitações deste estudo encontrase na reduzida amostra, de apenas 13 docentes, devido à pouca participação dos professores no curso de capacitação realizado. Assim, seria pertinente que futuros trabalhos procurassem abranger maior número de docentes, o que contribuiria para o aprofundamento do tema em análise.

\section{CONCLUSÕES}

Neste estudo, procurou-se discutir as declarações relativas aos medos, anseios, perspectivas, perdas e ganhos relacionados às afirmações do grupo investigado. Percebeu-se que, para cada pessoa, o envelhecimento apresenta inúmeras possibilidades de resultado final - 
pode-se ter, por exemplo, uma visão positiva, de transmissão de conhecimentos e sabedoria, como também uma visão negativa, limitando-o às degradações biológicas, dependendo dos caminhos escolhidos e dos determinantes desse processo. Ou seja, a identidade cultural de cada indivíduo, bem como o conjunto de experiências por cada um vivenciado, pode influenciar na autopercepção do envelhecimento e nas perspectivas desse processo.

Assim, é de suma importância que os professores, enquanto agentes mediadores da construção do conhecimento e formadores de opinião, tenham uma visão do envelhecimento humano de autonomia, integridade e independência, paraque diante dasua proximidade e importância, transmitam e conscientizem seus alunos a encararem o envelhecimento como um processo que é parte do ciclo natural da vida.

\section{AGRADECIMENTOS}

Os autores agradecem a M. Piccinini, por sua contribuição na coleta das informações, e a Pró-reitoria de Extensão da UNIPAMPA que, por meio do edital PROEXT/MEC de formação continuada, possibilitou a realização de um curso de capacitação docente para trabalhar o envelhecimento na escola.

\section{REFERÊNCIAS}

1. Motta AB. Visão antropológica do envelhecimento. In: Freitas EV, Py L, Neri AL, Cançado FAX, Gorzoni ML, Rocha SM, editores. Tratado de Geriatria e Gerontologia. 2. ed. Rio de Janeiro: Guanabara Koogan; 2006. p. 78-82.

2. Freitas MC, Queiroz TA, Sousa JAV. O significado da velhice e da experiência de envelhecer para os idosos. Rev Esc Enferm USP 2010;44(2):407-12.

3. Santos, MFS. Identidade e aposentadoria. São Paulo: Editora Pedagógica e Universitária; 1990. 88 p.

4. Mello PB, Piccinini AM, Rosa PV, Rosa LHT, Garcês SBB. Percepção dos cuidadores frente às dificuldades encontradas no cuidado diário de idosos dependentes institucionalizados. Estud interdiscip envelhec 2008; 13(2):259-74.

5. Mello PB, Piccinini AM, Rosa PV, Rosa LHT, Garcês SBB. Percepção dos acadêmicos dos cursos da saúde da Unicruz sobre o envelhecimento humano. RBCEH 2009;6(1):42-9.

6. Gvozd R, Dellaroza MSG. Velhice e a relação com idosos: o olhar de adolescentes do ensino fundamental. Rev Bras Geriatr Gerontol 2012;15(2):295-304.

7. Guerra ACLC, Caldas CP. Dificuldades e recompensas no processo de envelhecimento: a percepção do sujeito idoso. Ciênc Saúde Coletiva 2010;15(6):2931-40.

8. Moimaz SAS, Almeida MEL, Lolli LF, Garbin CAS, Saliba NA. Envelhecimento: análise de dimensões relacionadas à percepção dos idosos. Rev Bras Geriatr Gerontol 2009;12(3):361-75.

9. Silva CA, Fossatti AF, Portella MR. Percepção do homem idoso em relação às transformações decorrentes do processo do envelhecimento humano. Estud Interdiscip Envelhec 2007;12:111-26.

10. Aranha VC. Aspectos psicológicos do envelhecimento. In: Papaléo Netto M, organizador. Tratado de Gerontologia. São Paulo: Atheneu; 2007. p. 255-65.

11. Falsarella GR, Salve MGC. Envelhecimento e atividade física: análise das relações pedagógicas professor-aluno. Movimento \& Percepção 2007;7(10):61-75.

12. Freire P. Pedagogia da autonomia: saberes necessários à prática educativa. 43. ed. São Paulo: Paz e Terra; 2011.

13. Minayo MCS. O desafio do conhecimento: pesquisa qualitativa em saúde. 10. ed. São Paulo: Hucitec; 2007.

14. Cabral PKGF, Lopes RGC. Idosos reconstruindo-se com suas histórias [dissertação]. São Paulo: Programa de Pós-Graduação em Gerontologia da Pontifícia Universidade Católica; 2002.

15. Freitas EV, Py L, Neri AL, Cançado FAX, Gorzoni ML, Rocha SM, editores. Tratado de Geriatria e Gerontologia. 2. ed. Rio de Janeiro: Guanabara Koogan; 2006. 
16. Matsudo SM. Envelhecimento, atividade física e saúde. R Min Educ Fís 2002;10(1):195-209.

17. Duarte CP, Santos CL, Gonçalves AK. A concepção de pessoas de meia-idade sobre saúde, envelhecimento e atividade física como motivação para comportamentos ativos. Rev Bras Ciênc Esporte $2002 ; 23(3): 35-48$

18. Malta DC, Moura EC, Castro AM, Cruz DKA, Morais Neto OL, Monteiro CA. Padrão de atividade física em adultos brasileiros: resultados de um inquérito por entrevistas telefônicas, 2006. Epidemiol Serv Saúde 2009;18(1):7-16.

19. Veras R. Fórum. Envelhecimento populacional e as informações de saúde do PNAD: demandas e desafios contemporâneos. Introdução. Cad Saúde Pública 2007;23(10):2463-6.

20. Mendiondo MSZ, Bulla LC. Idoso, vida cotidiana e participação social. In: Terra NL, Dornelles B, organizadores. Envelhecimento bem-sucedido. Porto Alegre: EDIPUCRS; 2002. p. 271-81. 